\title{
Managing the acutely ill child
}

Children are different. It is 30 years since the Royal College of General Practitioners published its policy 'The Care of Children'1 (in response to the Committee on Child Health Services' Fit for the Future). ${ }^{2}$ The policy largely supported Donald Court's ideas to improve the care of children, but it balked at the new concept of a primary care paediatrician. However, the idea has not gone away and still forms an integral part of the strategic direction for the Royal College of Paediatrics and Child Health $(\mathrm{RCPCH}) .^{3}$ They point to the role such consultants have in much of Europe and the US, dealing with the acutely ill child, and the lack of formal paediatric training in a third of GPs. Yet, 34 million consultations with children are carried out by GPs each year, and our record on preventative measures, such as immunisations, is excellent. The RCPCH needs to double the consultant workforce just to deliver a consultant-led service, let alone deliver a comprehensive primary care service. Indeed, general paediatric consultant numbers have risen by only $7 \%$ per annum between 1999 and 2003, with community paediatric posts remaining static. ${ }^{4}$ Therefore, GPs will continue to be responsible for the care of this vulnerable group for years to come.

This must not make GPs complacent. The NHS has gone through unprecedented structural change recently and is now looking to improve the care of all patients through clinical change.

The government's green paper Every Child Matters, published in 2003, ${ }^{5}$ and the Children Act 2004 set the environment for a complete change in the care of children. The National Service Framework (NSF) for Children, Young People and the Maternity Services, published in the autumn of 2004 , set out a 10-year programme to improve children's health with 11 standards to be met. ${ }^{6}$ Lord Darzi's review, due to be published in June 2008, includes children's health as one of the eight areas on which each region is to focus. As a result of the report by Lord Laming into the death of Victoria Climbé, ${ }^{7}$ children's trusts (or at least arrangements that produce integrated working) are required to be up and running by the end of this year.

For those of us in general practice, many of these policy changes have seemed distant and irrelevant; the loss of midwife and health visitor colleagues from our premises being the only outward sign of change. It is a source of concern that general practice might be sidelined by these changes; as it is distant, both geographically and professionally, from the new child centres.

The NSF addresses this by suggesting that there are five possible ways that general practice could be engaged in the cooperation arrangements essential to improve childcare and prevent fragmentation of care: firstly, because child protection is a core part of our services; secondly, through enhanced services; thirdly, by audit of care against the NSF standards; fourthly, by using the Quality and Outcomes Framework (QOF); and finally, through guidance from the National Institute for Health and Clinical Excellence (NICE).

In short, every one of the policies and plans put in place over the past 30 years has been an attempt to improve the care of children. As GPs are central professionals in the lives of children and their families, it is vital that we play a full part in the development of clinical services and ensure our care of children is based on the latest evidence. Guidelines can form an influence for change in general practice. This should not be seen as a threat. In clinical areas where GPs work with sound guidelines, such as in the management of asthma, they have demonstrated high standards of care. Only one in 50 children is referred to a paediatrician each year; this rate has not changed for more than a decade. Asthma, the top reason for referral in 1988 , does not even feature in the top five now, with GPs largely taking on the care of children with this condition. ${ }^{8}$

However, there are concerns, as highlighted by Anthony Harnden's editorial in the $B M J,{ }^{9}$ following the publication of the Feverish IIIness in Children guidance from NICE. ${ }^{10} \mathrm{He}$ expressed that it was premature for guidance to be suggesting that every febrile child should routinely have their temperature, pulse, respiratory rate, and capillary refill time measured. ${ }^{9}$ Good primary care-based evidence is either scarce or simply does not exist. When working on Feverish Illness in Children, the Guideline Development Group found much good 'first presentation' evidence, but this was usually from emergency room or other hospital-based services, not general practice. ${ }^{10}$ The argument goes that symptoms and signs used in secondary care might have a different predictive value when used in primary care. More objective biomedical measures, such as heart rate, respiratory rate, and capillary refill time, may not be as useful in a primary care setting where softer more holistic signs, such as appearing ill to the professional, are felt to be more valuable. ${ }^{11}$

What is clear from the two papers in this month's BJGP is that we still have a long way to go until feverish children are managed in a coherent and effective way in primary care. ${ }^{12,13}$

Monteny and colleagues from Rotterdam ${ }^{12}$ demonstrate, in their study on the use of telephone contact to triage children with fever, that their current guideline from the Dutch College of General Practitioners does little to reduce the number of children having a face-toface consultation with a GP. The researchers found that red-flag symptoms were reported in large numbers raising the validity of these alarm symptoms. Certainly, in the Guideline Development Group's research for quality papers we found the traditional symptoms of dehydration as reported by parents (low urine output, decreased oral intake, and a history of vomiting or diarrhoea) to be poor predictors of dehydration, while sunken fontanelle, dry mouth, sunken eyes, absence of tears, and poor overall appearance are individually better signs of dehydration to elicit from parents, being more sensitive and displaying moderate observer agreement. ${ }^{14}$ It was heartening to see that parental concern was a major predictor for a further consultation. Good 
primary care has always listened to patients' and parents' concerns and taken them seriously.

It is clear from Thompson and colleagues' paper that GPs currently rely heavily on general observation of ill children, with few using pulse, respiratory rate, or capillary refill time as part of their routine examination. ${ }^{13}$ Many do not use a thermometer. The authors question the diagnostic value and accuracy of measuring pulse, respiratory rate, capillary refill time, or temperature. Measuring respiratory rate has moderate to poor interobserver agreement ( $\kappa=-0.04$ to 0.4 ), but poor overall appearance is little better $(\kappa=$ 0.18 to 0.61$).{ }^{14}$ However, this is no reason not to carry out basic measurements that have been shown, with all their failings, to offer useful, predictive help in detecting sick children.

In addition, the fragmentation of primary care makes it more important that our contemporaneous notes offer more to the next clinician trying to assess the child than a simple note suggesting the child looked well. This has become more important with our relinquishing of out-ofhours care. The need to ensure continuity of care for these sick children effectively, and to provide support to other clinicians managing these children later, calls for good objective notes of a better standard than the aide memoire approach GPs have used in the past to jog their own memories.

Central to this argument is whether technical, scientific evidence is more effective in detecting illness than Aristotle's phronesis or practical wisdom; the science of medicine versus the art, if you like.
Neither approach alone will provide the best care for children. The good doctor uses scientific knowledge and phronesis to develop their clinical judgement. Improvement in scientific knowledge enhances our clinical judgement, rather than damaging it. ${ }^{11}$

GPs remain central in the care of children. If we are to offer children good primary care we must be ready to work hard to prevent further fragmentation of the primary healthcare team. As senior members of the NHS we must make ourselves more available to work on NICE guideline groups, and be willing to work on developing good primary care-based research. Without our involvement this work will continue but its value for the GP will be diminished. Lastly, however, we must continue to practice good medicine, using our scientific knowledge, communication skills, and humanity. As Professor Downie put it, a good doctor individualises the generalised evidence available. ${ }^{15}$

\section{James AH Cave,}

GP Partner, The Downland Practice, Chieveley, Newbury; Member of the NICE Guideline Development Group for Feverish IIIness in Children; and Clinical Lead for South Central Region Next Stage Review

\section{REFERENCES}

1. Royal College of General Practitioners. College policy: the care of children. J R Coll Gen Pract 1978; 28: 553-556.

2. Court SDM. Fit for the future. Report of the Committee on Child Health Services. Cmnd 6684. London: HMSO, 1976.

3. Royal College of Paediatrics and Child Health. The Next Ten Years, 2002. http://www.rcpch.ac.uk (accessed 7 Mar 2008).
4. Royal College of Paediatrics and Child Health Supporting Services for Children: a workforce consensus, 2005. http://www.rcpch.ac.uk (accessed 7 Mar 2008).

5. Department for Education and Skills. Every child matters. Cm5860. London: The Stationery Office, 2003.

6. Department of Health, Department for Education and Skills. National Service Framework for children, young people and the maternity services. London: The Stationery Office, 2004.

7. Laming Lord. The Victoria Climbé Inquiry. Report of an inquiry by Lord Laming. http://www.victoriaclimbie-inquiry.org.uk/finreport/finreport.htm (accessed 10 Mar 2008).

8. Bhrolchain C. Who should provide primary care for children. Arch Dis Child 2004; 89: 116-117.

9. Harnden A. Recognising serious illness in feverish young children in primary care. BMJ 2007; 335(7617): 409-410.

10. National Institute for Health and Clinical Excellence. Feverish illness in children - assessment and initial management in children younger than 5 years, 2007. (NICE clinical guideline No. 47) http://guidance.nice.org.uk/CG47 (accessed 7 Mar 2008).

11. Van den Bruel A. Signs and symptoms for diagnosis of serious infections in children. Br J Gen Pract 2007; 57(540): 538-546.

12. Monteny M, Berger MY, van der Wouden JC, et al. Triage of febrile children at a GP cooperative: determinants of a consultation. Br J Gen Pract 2008; 58(549): 242-247.

13. Thompson M, Mayon-White R, Harnden A, et al. Using vital signs to assess children with acute infections: a survey of current practice. Br J Gen Pract 2008; 58(549): 236-241.

14. Steiner $M$, DeWalt $D$, Byerley J. Is this child dehydrated? JAMA 2004; 291(22): 2746-2754.

15. Downie RS, Macnaughton. Clinical judgement evidence in practice. Oxford: Oxford University Press, 2000 .

DOI: 10.3399/bjgp08X279706

\section{ADDRESS FOR CORRESPONDENCE:}

\section{James Cave,}

The Downland Practice, The Surgery,

East Lane, Chieveley, Newbury, RG20 8UY.

E-mail: ectopicmailbox-bjgp@yahoo.co.uk

\section{Place of death - how much does it matter? The priority is to improve end-of-life care in all settings}

Increasing patient choice is at the heart of current UK health service policy. At the end of life the focus is on eliciting patients' preferences for where end-of-life care is delivered, facilitating death at home when desired, and preventing crisis admissions in the last few days of life. ${ }^{1}$

Less than one-fifth (18.5\%) of deaths from all causes in England and Wales currently occur at home. More than half of all deaths $(58.3 \%)$ occur in hospital, with evidence of a slow but steady decline in 